\title{
Implementation process brief: Integrated family planning and HIV services at the community level in Kenya
}

Wilson Liambila

Population Council

Sara Chace Dwyer

Population Council

Charlotte E. Warren

Population Council

Aparna Jain

Population Council

Melsa Lutomia

See next page for additional authors

Follow this and additional works at: https://knowledgecommons.popcouncil.org/departments_sbsr-rh

Part of the Community Health and Preventive Medicine Commons, Demography, Population, and Ecology Commons, Family, Life Course, and Society Commons, International Public Health Commons, Medicine and Health Commons, and the Women's Health Commons How does access to this work benefit you? Let us know!

\section{Recommended Citation}

Liambila, Wilson, Sara Chace Dwyer, Charlotte E. Warren, Aparna Jain, Melsa Lutomia, Jane Loech, and Elizabeth Washika. 2020. "Implementation process brief: Integrated family planning and HIV services at the community level in Kenya," Programmatic Brief. Washington, DC: Population Council, The Evidence Project. 


\section{Authors}

Wilson Liambila, Sara Chace Dwyer, Charlotte E. Warren, Aparna Jain, Melsa Lutomia, Jane Loech, and Elizabeth Washika 


\section{Implementation process brief: Integrated family planning and HIV services at the community level in Kenya}

\section{PROGRAMMATIC BRIEF}

\section{BACKGROUND}

In 2016 there were 1.6 million people living with HIV in Kenya; of whom 57 percent were women aged 15 years and older; and 71 percent of these women received ART [1]. Evidence suggests that many women, including those living with HIV, are at risk of unintended pregnancies. Prevention of unintended pregnancies is a key component of a comprehensive strategy to eliminate mother-to-child HIV transmission (MTCT), and an effective strategy to reduce maternal mortality among those with HIV. While efforts have improved women's access to family planning (FP) in health facilities (contraceptive prevalence rate in Kenya is $58 \%$, in Busia county $56 \%$ ) [2], to date little has been done to understand the potential of providing integrated $\mathrm{FP} / \mathrm{HIV}$ services to women closer to their homes through the formal community health system structure.

In Kenya the national Community Health Strategy structure includes Community Health Committees (CHCs) that manage health activities for Community Units (CUs) of approximately 1,000 households or 5,000 people. To ensure long term self-reliance of community-based service delivery, each CU includes around 15 Community Health Volunteers (CHVs) who provide a range of health services (preventive, promotive and a few curative health services) to people in their communities. Community Health Extension Workers (CHEWs) supervise CHVs and link the $\mathrm{CHCs}$ to the primary health care facilities.

The Population Council through the Evidence Project with funding from PEPFAR/USAID, studied the feasibility and acceptability of integrating FP and HIV services at the community-level for women living with HIV. The intervention focused on building a supportive environment for $\mathrm{CHV}$ s to provide integrated FP/HIV services.
A series of activities were undertaken to develop the approach for integrated FP/HIV service delivery at the community-level, including stakeholder meetings, a review of learning and integration materials, adaption of CHV learning materials, workforce development activities, and supportive supervision.

This brief describes the intervention process and challenges that were encountered. A description of the study's methodological approach and results are not presented here but are available on the Evidence Project website [3].

\section{c 2013 Karolina Lagiewka, Courtesy of Photoshare}

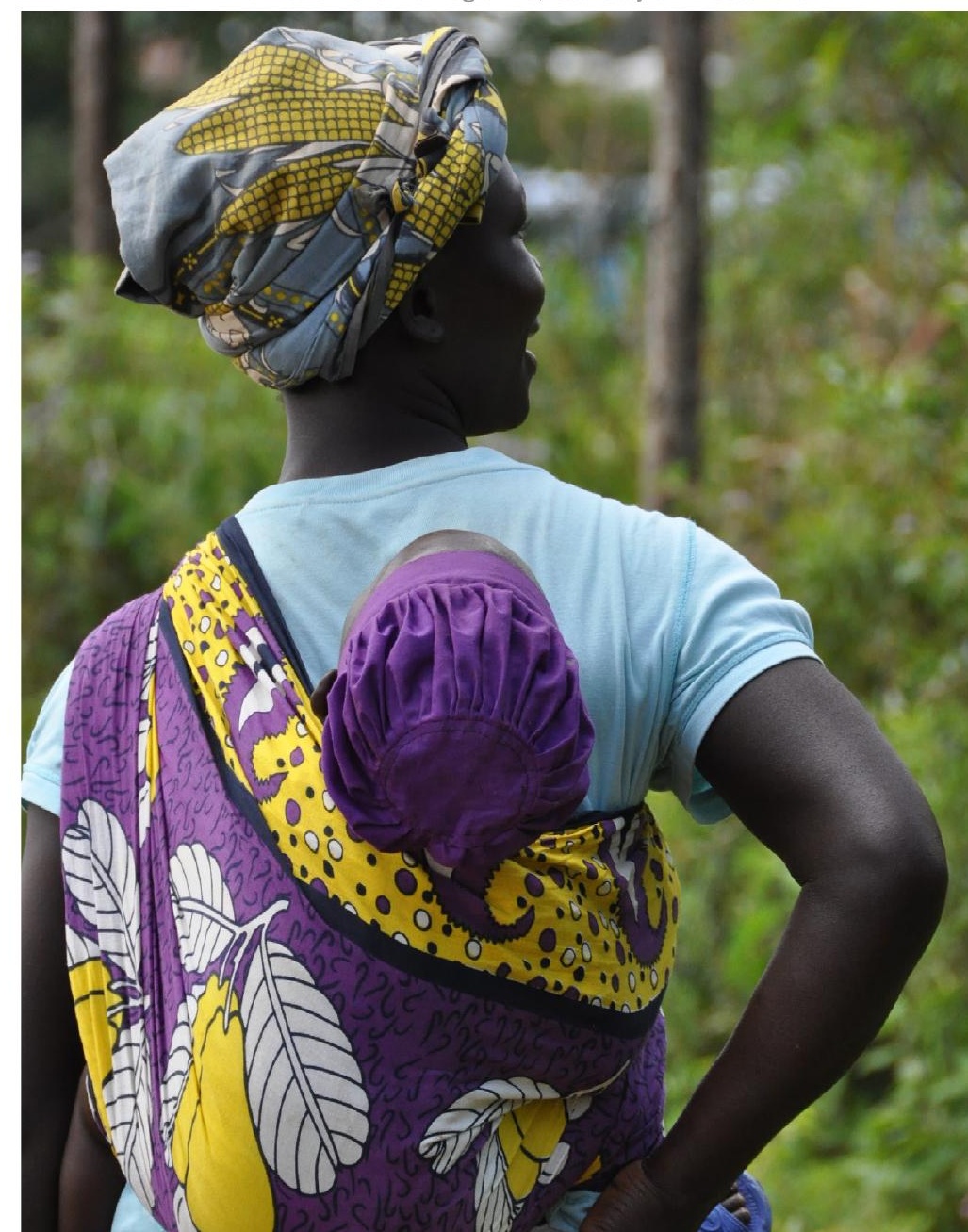


This Evidence Project study took place in Samia (intervention sites) and Butula (comparison sites) sub-counties in Busia county, Western Kenya. It was conducted collaboratively with the County and Sub-county health management teams (CHMT and SCHMT). The Evidence Project and CHMT and SCHMT members subsequently held: (1) sensitization meetings with CHEWs, CHCs, and primary health centers; and (2) reviewed existing learning materials on community health including curricula, commodities, and human resources (e.g., Kenya Community Health Strategy [4]), FP/HIV integration materials (e.g., BCS+ [5]) , and $\mathrm{CHV}$ household registers and reporting forms. Results from the review of learning and integration materials, and the sensitization meetings helped shape the intervention, including:

\section{Adaptation of the training materials to:}

- Increase emphasis on FP counseling for CHV trainees to meet the needs of women living with HIV;

- Expand the training session on stigma and discrimination; and;

- Refine FP terminology for the training materials.

2. Align the community scorecard with the national community health strategy.

3. Identify workforce development activities, including training $\mathrm{CHVs}$ in integrated services, training CHEWs to manage and support CHV activities and

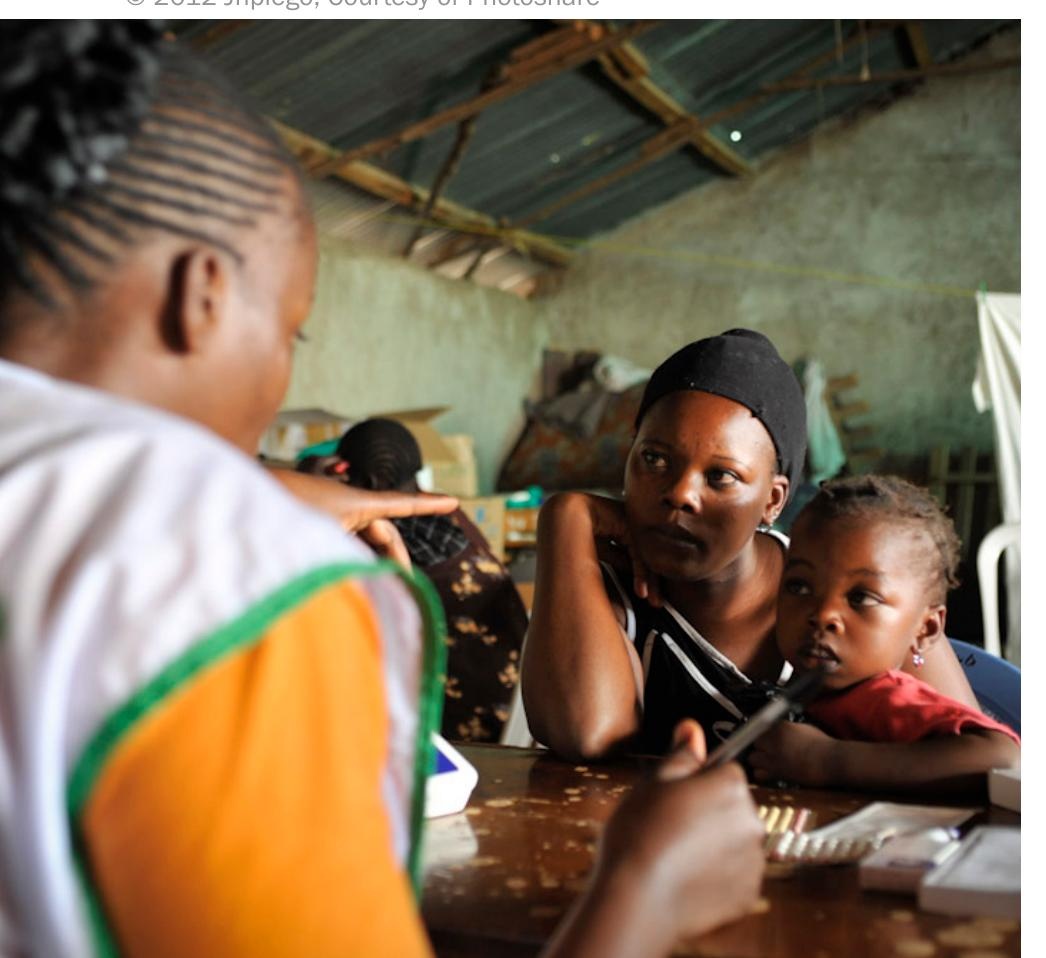

identify the appropriate income generation activities (IGA) to include in a business skills training for CHCs.

4. Modify the existing supervision assessment tool to enable the health management teams to support $\mathrm{CHVs}$ in providing integrated FP/HIV activities.

\section{KEY IMPLEMENTATION ACTIVITIES}

- Stakeholder meetings

- Review of learning and integration materials

- Adaptation of learning materials

- Workforce development activities

- Supportive supervision

\section{Adaptation of learning materials}

The Evidence Project and Busia CHMT reviewed the training materials and subsequently incorporated additional components into the $\mathrm{CHV}$ training curriculum to ensure $\mathrm{CHV}$ s had the knowledge and skills to effectively integrate FP/ HIV services at the community level. These included training sessions on: (a) providing high quality FP counseling; (b) providing voluntary FP methods while ensuring informed choice; and (c) recognizing and reducing HIV-related stigma and discrimination. In addition, the project team reviewed the IGAs/business content in the CHV manual for relevance and appropriateness.

\section{Workforce development activities}

Table 1 outlines the training and IGA activities that were completed with different members of the community-health structure. Because the sustainability of $\mathrm{CHV}$ integrated FP/HIV services is linked to the function of the community health structure, trainings were also held with $\mathrm{CHEWs}$ and $\mathrm{CHC}$ members.

Most CHVs were not routinely compensated for their work as community health workers apart from inconsistent stipends made by NGOs or donors. Therefore, the Ministry of Health in the County Government of Busia requested the Evidence Project to train $\mathrm{CHVs}$ and the $\mathrm{CHC}$ members in income-generating activities 


\begin{tabular}{|c|c|c|}
\hline CADRE & TOPICS COVERED & DETAILS \\
\hline CHEWs & $\begin{array}{l}\text { - Key roles and responsibilities of CHVs } \\
\text { - Importance of integrating FP and HIV services at the community level } \\
\text { - Essential skills for providing FP counseling; and pills and condoms } \\
\text { - Rumors, myths and misperceptions related to FP methods } \\
\text { - Importance of record keeping for providing FP services }\end{array}$ & $\begin{array}{l}\text { - } 40 \text { CHEWs trained. } \\
\text { - Facilitated by Busia CHMT and } \\
\text { Samia SCHMT. }\end{array}$ \\
\hline CHVs & $\begin{array}{l}\text { - Skills for FP counseling using an adaptation of BCS+ } \\
\text { - Establish rapport, use active listening skills } \\
\text { - } \text { family size), tailor counseling as appropriate: } \\
\text { - } \quad \text { Identify client's needs related to reproductive intentions, concern over side effects, } \\
\text { effectiveness, and timing of use } \\
\text { - Provide condoms and oral contraceptive pills } \\
\text { - Refer if client chooses long-acting reversible or permanent methods (IUD, implant, or } \\
\text { sterilization) } \\
\text { - HIV treatment and care, routine HIV information and education, and risk assessment, } \\
\text { refer for HIV services as needed } \\
\text { - HIV-related stigma and discrimination } \\
\text { - Document services provided }\end{array}$ & $\begin{array}{l}\text { - } 324 \text { CHVs attended 5-day training. } \\
\text { - } 11 \text { batches of } ~ 32 \text { people per } \\
\text { training. } \\
\text { - } \quad \text { Facilitated by } 2 \text { CHEWs per training. }\end{array}$ \\
\hline $\begin{array}{l}\text { CHC } \\
\text { members }\end{array}$ & $\begin{array}{l}\text { - Build capacity to support CU activities } \\
\text { - Community- level meetings, education and awareness campaigns } \\
\text { health services } \\
\text { - Conduct IGAs. A training on IGAs included: } \\
\text { Scope of sustainable livelihoods, marketing, household/livelihood enterprise } \\
\text { development, business ideas, scope of trading in community, business records, } \\
\text { record keeping, resource mobilization for business start-up, debt and credit man- } \\
\text { agement, financial literacy and group dynamics }\end{array}$ & $\begin{array}{l}\text { - } 84 \mathrm{CHC} \text { members participated in } \\
\text { 2-day training. } \\
\text { - } 2 \text { batches of } ~ 42 \mathrm{CHC} \text { members per } \\
\text { training. } \\
\text { - } 4 \text { facilitators from the Rural Educa- } \\
\text { tion and Economic enhancement } \\
\text { program per training }\end{array}$ \\
\hline
\end{tabular}

(IGAs) and business skills for agriculture and livestock-based activities (fish farming, poultry, farming, etc.). The acquisition of business skills provided opportunities for CUs to develop IGAs. This enabled CUs to offer consistent stipend payments to CHVs, and transportation reimbursements for $\mathrm{CHVs}$ who visited distant households, which in turn reduced the reliance on NGOs or donors to remunerate $\mathrm{CHVs}$.

\section{Supportive supervision}

Following the training (see Table 1), supportive supervision activities were implemented within the Kenyan Ministry of Health framework. Busia CHMT and SCHMT and the Evidence Project modified the existing supervision assessment tool to enable the health management teams to better: (a) encourage CHVs who were providing integrated FP-HIV services; (b) ensure quality service provision; and (c) build the capacity of the CHEWs who oversee CHV activities. The supervision activities strengthened the relationships between CHMT, SCHMT, and CHCs teams by providing opportunities to identify implementation issues (such as stockouts) and recognize good practice. During the supervision visits, CHMT, SCHMTs and CHEWs discussed with $\mathrm{CHVs}$ the regular and accurate use of household records, service-delivery logbooks, commodity tracking tool, referral forms and the BCS+ counseling tools. CHMT and SCHMT continue to use this modified supervision assessment tool with CHVs. 
Several challenges were encountered with the Ministry of Health (MoH), CHMT, SCHMT and the Evidence Project implementation of the intervention activities. These issues should be considered when implementing similar community-based programs in Kenya. First, a consistent supply of contraceptives (or other health commodities) is needed to ensure CHVs have the supplies to provide health services at community level. Second, extensive mapping of other NGO-funded activities (both current and anticipated) and government-led initiatives (including non-health activities) can help to avoid duplications and streamline efforts to improve quality of services provided at the community-level. Third, promoting new ways of working at the community-level takes time. The intervention period for this study was for only 10 months, which was insufficient to appropriately observe change in the functioning of CHCs and CHVs behaviors. Finally, to encourage sustainability, supportive supervision activities were designed and implemented within the existing community health structures. While this

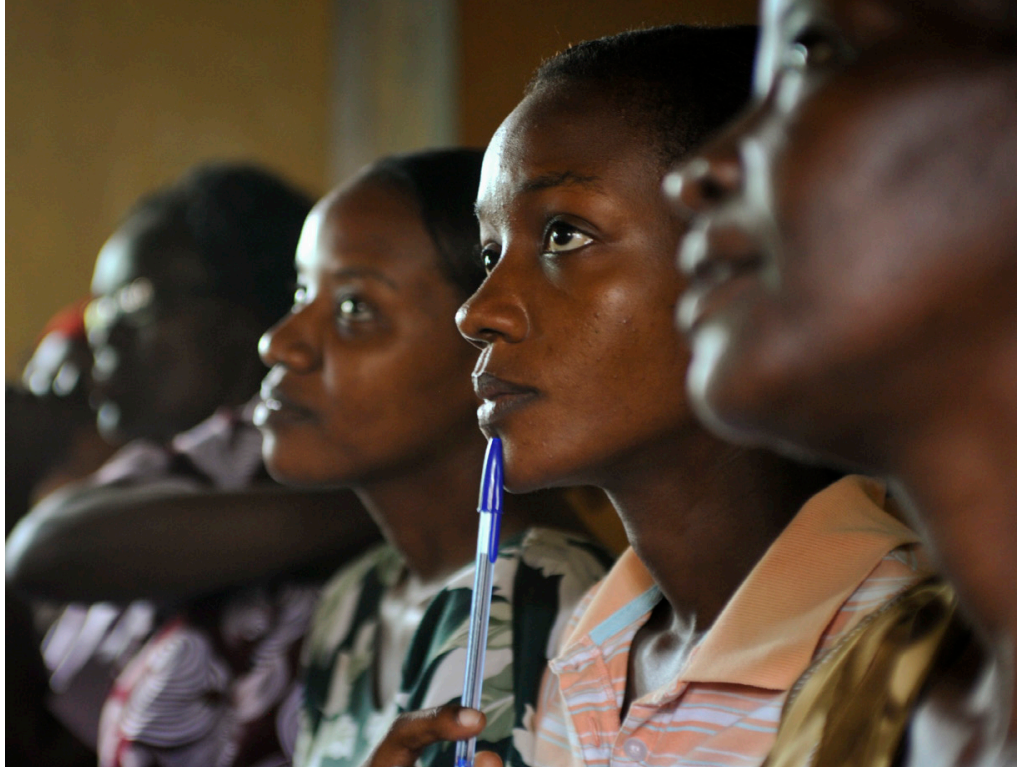

(c) 2012 John Kihoro/Tupange(Jhpiego Kenya), Courtesy of Photoshare

approach has potential benefits in the long run, the project experience short-term setbacks. The most critical being the high-turnover rates for CHEWs, who are responsible for managing $\mathrm{CHV}$ activities and providing supportive supervision. The project recommends reviewing the human resource strategy for the county

\section{REFERENCES}

${ }^{1}$ UNAIDS. 2017. Kenya Country Factsheet. Available: http://www.unaids.org/en/regionscountries/countries/kenya

${ }^{2}$ Kenya National Bureau of Statistics, Ministry of Health/Kenya, National AIDS Control Council/Kenya, Kenya Medical Research Institute, National Council for Population and Development/Kenya, and ICF International. 2015. Kenya Demographic and Health Survey 2014. Rockville, MD, USA: Kenya National Bureau of Statistics, Ministry of Health/Kenya, National AIDS Control Council/Kenya, Kenya Medical Research Institute, National Council for Population and Development/Kenya, and ICF International.

${ }^{3}$ Liambila, Wilson, et al. 2018. "Strengthening the Integration of Family Planning and HIV Services at the Community Level in Kenya," Research Report. Washington, DC \& Nairobi, Kenya: Population Council, The Evidence Project. http://evidenceproject.popcouncil.org/ resource/fp-hiv-integration-kenya/

${ }^{4}$ Republic of Kenya Ministry of Health. 2014. “Strategy for Community Health 2014-2019." Ministry of Health, Community Unit. Available: https://www.medbox.org/ke-community-health/kenya-strategy-for-community-health-2014-2019/preview?

${ }^{5}$ Population Council. 2015. “The Balanced Counseling Strategy Plus: A Toolkit for Family Planning Service Providers Working in High HIV/ STI Prevalence Settings." 3rd edition. Available: https://www.popcouncil.org/research/the-balanced-counseling-strategy-plus-a-toolkit-for-family-planning-service

\section{USAID Evidence}

The Evidence Project is made possible by the generous support of the American people through the United States Agency for International Development (USAID) under the terms of cooperative agreement no. AID-OAA-A-13-00087. The contents of this document are the sole responsibility of the Evidence Project and Population Coun-

cil and do not necessarily reflect the views of USAID or the United States Government.

Front page photo credit: (c) 2013 Molly Snell, Courtesy of Photoshare

Suggested Citation: Liambila, Wilson, Sara Chace Dwyer, Charlotte Warren, Aparna Jain, Melsa Lutomia, Jane Loech and Elizabeth Washika. 2019. “Implementation process brief: integrated family planning and HIV services at the community level in Kenya." Programmatic Brief. Washington, DC: Population Council, The Evidence Project.

For more information, go to evidenceproject.popcouncil.org_or contact Wilson Liambila at wliambila@popcouncil.org
The Evidence Project uses implementation science-the strategic generation, translation, and use of evidence-to strengthen and scale up family planning and reproductive health programs to reduce unintended pregnancies worldwide. The Evidence Project is led by the Population Council. 